\title{
The effects of weather, air pollutants, and Asian dust on hospitalization for asthma in Fukuoka
}

\author{
Kayo Ueda $\cdot$ Hiroshi Nitta $\cdot$ Hiroshi Odajima
}

Received: 26 January 2010/Accepted: 22 April 2010/Published online: 25 May 2010

(C) The Japanese Society for Hygiene 2010

\begin{abstract}
Objective We assessed the association of fluctuations in ambient temperature, air pollutants, and Asian dust (AD) events with the hospitalization of children for asthma in Fukuoka City.

Methods Data on emergency hospitalizations of children under 12 years of age for asthma were collected at Fukuoka National Hospital. We obtained air pollution and meteorological data for Fukuoka from the National Institute for Environmental Studies. Using a time-stratified case-crossover design, we estimated odds ratios (ORs) of hospitalization corresponding to a unit change in weather variables and concentration of air pollutants. We also evaluated the effect of $\mathrm{AD}$ events on asthma hospitalization with data stratified by days with or without an AD event. Results There were 3427 hospitalizations and $106 \mathrm{AD}$ events from 2001 to 2007 . We found that within-day temperature change rather than ambient temperature was associated with asthma exacerbation. In the multi-pollutant model, the ORs per $1{ }^{\circ} \mathrm{C}$ within-day drop and rise during the period from the hospitalization day to 3 days previously (lag3) were 1.033 [95\% confidence interval (CI) 1.0051.063] and 1.027 (95\% CI 0.995-1.060), rspectively. A $10 \mu \mathrm{g} / \mathrm{m}^{3}$ increase in suspended particulate matter (SPM) and nitrogen dioxide $\left(\mathrm{NO}_{2}\right)$ at lag2-lag3 were significantly associated with an increase in asthma hospitalization with
\end{abstract}

K. Ueda $(\bowtie) \cdot$ H. Nitta

Environmental Epidemiology Section,

Environmental Health Sciences Division,

National Institute for Environmental Studies,

16-2 Onogawa, Tsukuba 305-8506, Japan

e-mail: uedak@nies.go.jp

H. Odajima

Fukuoka National Hospital, Fukuoka, Japan
ORs of 1.041 (95\% CI 1.013-1.070) and 1.112 (95\% CI 1.022-1.209), respectively. We did not observe a significant association between asthma hospitalization and $\mathrm{AD}$ events.

Conclusions This study showed that temperature fluctuation, SPM, and $\mathrm{NO}_{2}$ were associated with an increased risk of hospitalization of children for asthma.

Keywords Asthma - Hospitalization - Temperature . Air pollution · Dust

\section{Introduction}

The prevalence of asthma, a chronic disorder of the airways accompanied by episodic airway obstruction, has been increasing among the younger members of the Japanese population $[1,2]$, while mortality due to asthma has shown a decreasing trend since the introduction of the corticosteroid inhaler [3]. One of the goals of asthma management is to prevent asthma exacerbations [4], and in order to achieve this goal, it is necessary to understand the effect of environmental factors that could trigger an asthma attack.

Both weather [5-8] and air pollutants [7-13] have been recognized as important environmental factors that have adverse effects on asthma. Most of these factors have been the focus of extensive research, but there are a number of environmental factors that have not yet been fully evaluated in terms of their effect on asthma.

First, it has recently been suggested that temperature fluctuation rather than ambient temperature itself is related to cardiovascular disease $[14,15]$. However, we are unaware of studies that have evaluated the effect of temperature fluctuation on the exacerbation of asthma. One of the 
hypotheses of this study is that fluctuations in ambient temperature could increase the risk of asthma hospitalization; consequently, we have examined the association between temperature fluctuation and asthma hospitalization.

Second, it is necessary to evaluate the health effects of air pollutants. Air pollutants have also been emphasized as important triggers of asthma exacerbation [7-13], and several studies have reported an effect after a lag of a few days following exposure [8, 10-12]. In Japan, there have been a few studies that evaluated the short-term effect of air pollutants on asthma exacerbation, but these focused on the effect on asthma of exposure on the same day and on the previous day $[6,13]$. In this study, we evaluated the lagged effect of air pollutants for up to 6 days prior to hospitalization.

Third, it may be necessary to consider regional specific environmental exposures. Fukuoka is an urban city located in the northern part of Kyushu Island in Japan, close to the Asian continent, and the city experiences Asian dust (AD) events more frequently than other parts of Japan. An AD event is the phenomenon in which mineral dust originating from the Gobi and Taklamakan deserts of China and Mongolia is lifted by wind and transported to the Pacific region, sometimes even to the west coast of North America [16]. Although a few studies evaluating the effects of AD events on asthma have been published [17, 18], little data are available on the effects of AD events on health in Japan. It has been suggested that $\mathrm{AD}$ is contaminated by various chemical components [19] and microorganisms [20] through the transportation mechanism and that it is possible that particles from $\mathrm{AD}$ have greater toxic effects than those from local air pollution. In this context, our aim is to address the more specific question of whether exposure to particles in $\mathrm{AD}$ has an impact on asthma hospitalization.

Therefore, the overall aim of this study was comprehensively examine the effects of fluctuations in ambient temperature, air pollutants, and AD events in Fukuoka City on the exacerbation of asthma in children using hospital data.

\section{Materials and methods}

Patient data

This study used information obtain from anonymous unlinked data. Data on emergency hospitalizations for asthma from January 2001 to December 2007 were collected at Fukuoka National Hospital in Fukuoka. The data included information on sex and age of the patient, the date of admission, the date of discharge, and the code of the International Classification of Diseases (10th revision). The subjects of this study were children under 12 years of age.
Environmental data

Data on air pollutants and weather conditions were obtained from the atmospheric environment database of the National Institute for Environmental Studies. The air pollutants studied were suspended particulate matter (SPM), photochemical oxidants $(\mathrm{Ox})$, nitrogen dioxide $\left(\mathrm{NO}_{2}\right)$, and sulfur dioxide $\left(\mathrm{SO}_{2}\right)$. We used hourly measurements at the closest monitoring stations to Fukuoka National Hospital. Under the Japanese Air Quality Standard, SPM is defined as airborne particles with a $100 \%$ cut-off level at $10 \mu \mathrm{m}$ aerodynamic diameter. SPM monitored in Japan is theoretically assumed to be particles with a diameter of $<7 \mu \mathrm{m}$ (approximately) with a 50\% cut-off level. Ox is defined as mixtures of ozone and other secondary oxidants generated by a photochemical reaction, and considered to be a proxy for ozone. Data on AD events were obtained from the Japan Meteorological Agency [21]. The occurrence of an $\mathrm{AD}$ event was generally determined by visibility-based observation [22].

Statistical analyses

To evaluate the association between air pollutants and the risk of hospitalization for asthma, we used a time-stratified case-crossover design. The case-crossover analysis was developed to assess the acute effects of transient exposure [23], and its application in the field of air pollutant epidemiology has recently increased. In this design, withinsubject comparisons are made between a case period and control periods. In our study, a case period was defined as the day of hospitalization. The selection of appropriate control periods is important for obtaining valid estimates; therefore, as control periods, we chose the same day of the week in the same month of the same year as the case period. Using this control selection strategy, we expected to be able to adjust for the effects of long-term trend, seasonality, and day of week through the design of the study.

We estimated the odds ratios (ORs) of hospitalization using conditional logistic regression. We controlled for 4-day averaged daily mean ambient temperature and relative humidity from the case day (lag0) to 3 days prior (lag3). We calculated the maximum within-day drop and rise in temperature as follows. Based on hourly temperature data, we identified all local minima and maxima for each day. We then defined the maximum within-day temperature drop as the largest difference between any local maximum temperature and the subsequent local minimum temperature. Similarly, we defined the maximum within-day rise in temperature as the largest difference between any local minimum temperature and the subsequent local maximum temperature. We hypothesized that the time from exposure 
to hospitalization would range from a few hours to a few days. Therefore, we included the maximum daily temperature drop and rise, respectively, during the period from the day of hospitalization to 3 days prior to hospitalization $\left(T_{\text {drop03 }}, T_{\text {rise03 }}\right)$ in the model. We examined the 24 -h mean concentration of SPM, Ox, $\mathrm{NO}_{2}$, and $\mathrm{SO}_{2}$. To evaluate the lag effect of air pollutants, we applied the lag-stratified distributed lag model [24] and entered the averaged concentration of air pollutants during lag0-lag1 (lag01), during lag2-lag3 (lag23), and during lag4-lag6 (lag46) simultaneously in the model. Similar analyses were repeated using the data stratified by season (May-October, NovemberApril) and sex.

We examined whether the risk of asthma hospitalization increased on the days with an $\mathrm{AD}$ event (AD days) compared to those without an AD event (non-AD days). We estimated the OR of hospitalization on AD days, controlling for weather variables. The health effects of particles from AD may differ from locally produced particulate air pollutants. Therefore, we also compared the effect estimates of SPM between the AD days and non-AD days. We stratified the data by whether the case day was an AD day or non-AD day. To test whether there was any difference in the effect of SPM between AD days and non-AD days, we created a binary variable indicating whether the hospitalization occurred on an AD day or a non-AD day and added an interaction term between SPM concentration and AD days into the model.

The results were presented as ORs with $95 \%$ confidence intervals (CI).

\section{Results}

During the study period, there were 3427 hospitalizations of children aged 0-12 years for asthma (Table 1). Of these, about $60 \%$ were male and over $60 \%$ were children under 6 years of age.

There were $106 \mathrm{AD}$ events observed in Fukuoka from 2001 to 2007 (Table 2). Although most occurred from March to May, a few AD events were observed in the fall and winter. Table 3 shows the summary statistics of air pollutants and meteorological variables. The mean withinday temperature drop and rise were 4.1 and $5.3^{\circ} \mathrm{C}$, respectively. The comparison of the environmental variables showed that the mean concentration of SPM on AD days was almost 1.8 -fold greater than that on non-AD days. The levels of $\mathrm{Ox}$ and $\mathrm{SO}_{2}$ on $\mathrm{AD}$ days were also higher than those on non-AD days.

We initially estimated the effects of $T_{\text {drop03 }}$ and $T_{\text {rise } 03}$ adjusted for 24-h mean temperature and relative humidity. A significant association was observed between both $T_{\mathrm{drop} 03}$ and $T_{\text {rise03 }}$ and asthma hospitalization in this basic
Table 1 Summary of study subjects

\begin{tabular}{lc}
\hline Demographic variables & No. of hospitalizations $(\%)$ \\
\hline All subjects & $3427(100.0)$ \\
Sex & $2078(60.6)$ \\
Male & $1341(39.1)$ \\
Female & $8(0.2)$ \\
Missing & \\
Age & $673(19.6)$ \\
$0-1$ year & $1506(43.9)$ \\
2-5 years & $1248(36.4)$ \\
6-12 years & \\
\hline
\end{tabular}

Table 2 Number of days when Asian dust events were observed in Fukuoka, 2001-2007

\begin{tabular}{llc}
\hline Year & Frequency & \\
\cline { 2 - 3 } & Full year & March-May \\
\hline 2001 & 30 & 29 \\
2002 & 25 & 23 \\
2003 & 2 & 2 \\
2004 & 10 & 10 \\
2005 & 10 & 7 \\
2006 & 13 & 13 \\
2007 & 16 & 14 \\
\hline
\end{tabular}

model. The ORs corresponding to an increase of $1^{\circ} \mathrm{C}$ in $T_{\mathrm{drop} 03}$ and $T_{\text {rise03 }}$ were 1.030 (95\% CI $\left.1.003-1.057\right)$ and 1.040 (95\% CI 1.013-1.068), respectively.

Table 4 shows the ORs of asthma hospitalization per unit increase in each air pollutant. In the single-pollutant models where we adjusted for ambient temperature, relative humidity, $T_{\mathrm{drop} 03}$ and $T_{\text {rise03 }}$, we found that a 10 -unit increase in SPM and $\mathrm{NO}_{2}$ at lag23 was significantly associated with an increase in asthma hospitalization, with ORs of 1.041 (95\% CI 1.013-1.070) and 1.112 (95\% CI 1.0221.209), respectively (Table 4). There were no significant associations between $\mathrm{Ox}$ and $\mathrm{SO}_{2}$ and asthma hospitalization. We also applied the multi-pollutant model, including ambient temperature, relative humidity, $T_{\mathrm{drop} 03}, T_{\text {rise03 }}$, $\mathrm{SPM}, \mathrm{NO}_{2}, \mathrm{Ox}$, and $\mathrm{SO}_{2}$. Although the association between asthma and air pollutants became insignificant (Table 4), the central point estimates and lag pattern for SPM, Ox, and $\mathrm{NO}_{2}$ remained similar to those from the single-pollutant models. In the multi-pollutant model, the ORs per $1^{\circ} \mathrm{C}$ $T_{\text {drop03 }}$ and $T_{\text {rise03 }}$ were 1.033 (95\% CI 1.005-1.063) and 1.027 (95\% CI 0.995-1.060), respectively.

The season-stratified analyses did not reveal any substantial difference in the effect estimates of SPM, Ox, and $\mathrm{NO}_{2}$ between the warm season (May-October) and the cool season (November-April). The effect estimates of $\mathrm{SO}_{2}$ at 
Table 3 Summary of 24-h mean concentration of air pollutants and meteorological variables

\begin{tabular}{|c|c|c|c|c|c|c|c|}
\hline \multirow[t]{2}{*}{ Variables } & \multirow{2}{*}{$\begin{array}{l}\text { No. of days } \\
\text { analyzed }\end{array}$} & \multirow[t]{2}{*}{ Mean (SD) } & \multirow[t]{2}{*}{ Minimum } & \multicolumn{3}{|c|}{ Percentiles } & \multirow[t]{2}{*}{ Maximum } \\
\hline & & & & 25 th & 50 th & 75 th & \\
\hline \multicolumn{8}{|l|}{ Air pollutants } \\
\hline \multicolumn{8}{|l|}{$\operatorname{SPM}\left(\mu \mathrm{g} / \mathrm{m}^{3}\right)$} \\
\hline All days & 2506 & $35.9(17.7)$ & 7.9 & 23.9 & 31.2 & 43.8 & 213.0 \\
\hline AD-days (March-May) & 97 & $62.8(34.7)$ & 22.1 & 44.0 & 53.6 & 67.7 & 213.0 \\
\hline Non-AD days (March-May) & 543 & $34.3(13.4)$ & 10.6 & 25.1 & 31.8 & 40.5 & 95.2 \\
\hline \multicolumn{8}{|l|}{$\mathrm{Ox}(\mathrm{ppb})$} \\
\hline All days & 2466 & $26.7(11.8)$ & 1.2 & 17.6 & 26.4 & 34.9 & 69.6 \\
\hline AD-days (March-May) & 94 & $39.5(9.5)$ & 19.1 & 33.0 & 39.9 & 44.8 & 69.6 \\
\hline Non-AD days (March-May) & 517 & $35.7(10.5)$ & 7.9 & 28.3 & 36.7 & 43.2 & 65.5 \\
\hline \multicolumn{8}{|l|}{$\mathrm{NO}_{2}(\mathrm{ppb})$} \\
\hline All days & 2485 & $18.1(7.5)$ & 2.3 & 12.5 & 17.5 & 23.2 & 50.6 \\
\hline AD-days (March-May) & 92 & $17.6(6.9)$ & 4.5 & 12.5 & 17.5 & 22.3 & 35.0 \\
\hline Non-AD days (March-May) & 537 & $17.9(7.2)$ & 3.5 & 12.2 & 17.5 & 22.9 & 45.8 \\
\hline \multicolumn{8}{|l|}{$\mathrm{SO}_{2}(\mathrm{ppb})$} \\
\hline All days & 2494 & $4.5(1.6)$ & 0.9 & 3.3 & 4.3 & 5.3 & 14.2 \\
\hline AD-days (March-May) & 91 & $5.5(1.6)$ & 2.4 & 4.3 & 5.5 & 6.6 & 9.4 \\
\hline Non-AD days (March-May) & 545 & $4.9(1.7)$ & 0.9 & 3.7 & 4.7 & 6.0 & 11.3 \\
\hline \multicolumn{8}{|l|}{ Meteorological variables } \\
\hline \multicolumn{8}{|l|}{ Temperature $\left({ }^{\circ} \mathrm{C}\right)$} \\
\hline All days & 2551 & $17.3(7.8)$ & -1.4 & 10.5 & 17.7 & 24.0 & 31.9 \\
\hline AD-days (March-May) & 98 & $14.9(3.5)$ & 5.1 & 12.8 & 14.6 & 16.5 & 24.2 \\
\hline Non-AD days (March-May) & 545 & $15.2(4.9)$ & 2.1 & 11.8 & 16.0 & 19.1 & 26.6 \\
\hline \multicolumn{8}{|c|}{ Within-day temperature drop $\left({ }^{\circ} \mathrm{C}\right)$} \\
\hline All days & 2556 & $4.1(1.7)$ & 0.2 & 2.9 & 4.0 & 5.2 & 12.3 \\
\hline AD-days (March-May) & 98 & $5.0(1.8)$ & 1.2 & 3.8 & 4.9 & 6.2 & 11.4 \\
\hline Non-AD days (March-May) & 546 & $4.4(1.9)$ & 0.8 & 3.1 & 4.2 & 5.4 & 12.3 \\
\hline \multicolumn{8}{|l|}{ Within-day temperature rise $\left({ }^{\circ} \mathrm{C}\right)$} \\
\hline All days & 2556 & $5.3(2.7)$ & 0.2 & 3.2 & 5.1 & 7.1 & 15.0 \\
\hline AD-days (March-May) & 98 & $5.9(3.3)$ & 0.6 & 2.9 & 5.5 & 8.7 & 12.6 \\
\hline Non-AD days (March-May) & 546 & $5.8(3.1)$ & 0.2 & 3.3 & 5.7 & 8.2 & 15.0 \\
\hline \multicolumn{8}{|l|}{ Relative humidity (\%) } \\
\hline All days & 2551 & $66.7(11.0)$ & 28.3 & 58.7 & 66.8 & 74.3 & 95.7 \\
\hline AD-days (March-May) & 98 & $57.8(10.8)$ & 28.3 & 51.0 & 57.8 & 65.4 & 84.9 \\
\hline Non-AD days (March-May) & 545 & $65.2(13.0)$ & 31.1 & 55.0 & 64.1 & 75.4 & 95.7 \\
\hline
\end{tabular}

$A D$ Asian dust, $S P M$ suspended particulate matter, $O x$ photochemical oxidants, $\mathrm{NO}_{2}$ nitrogen dioxide, $\mathrm{SO}_{2}$ sulfur dioxide, $p p b$ parts per billion, $S D$ standard deviation

lag01 were larger in the warmer season than those in the cooler season (Table 4). In the sex-stratified analyses, we did not find any substantial gender-related differences in the effect of each pollutant on asthma hospitalization.

Finally, we examined the effects of $\mathrm{AD}$ events on asthma hospitalization. The ORs of hospitalization on AD days adjusted for weather variables were 1.210 (95\% CI 0.946-1.548). The result using the data from March to May was similar (OR 1.182, 95\% CI 0.905-1.544). We also compared the effect of SPM on AD days and non-AD days (Table 5). No statistically significant difference was observed for the effect of SPM on asthma hospitalization by $\mathrm{AD}$ events.

\section{Discussion}

In this study, we assessed the effects of weather, air pollutants, and $\mathrm{AD}$ events on asthma hospitalization for children. We found that within-day temperature change - rather than absolute ambient temperature - was associated with asthma exacerbation. We also observed that an increase in SPM and 
Table 4 Odds ratios and 95\% confidence intervals of asthma hospitalization per unit increase in each air pollutant

\begin{tabular}{|c|c|c|c|c|}
\hline \multirow[t]{2}{*}{ Models } & \multirow[t]{2}{*}{ Mean } & \multicolumn{3}{|l|}{ Odds ratio $(95 \% \mathrm{CI})$} \\
\hline & & Full year & May-October & November-April \\
\hline \multicolumn{5}{|l|}{ Single-pollutant models } \\
\hline \multirow[t]{3}{*}{ SPM (per $10 \mu \mathrm{g} / \mathrm{m}^{3}$ ) } & lag01 & $0.980(0.954,1.007)$ & $0.989(0.950,1.029)$ & $0.962(0.927,0.999)$ \\
\hline & $\operatorname{lag} 23$ & $1.041(1.013,1.070)$ & $1.045(1.003,1.088)$ & $1.042(1.003,1.082)$ \\
\hline & $\operatorname{lag} 46$ & $0.995(0.966,1.025)$ & $1.001(0.959,1.046)$ & $0.981(0.941,1.023)$ \\
\hline \multirow[t]{3}{*}{ Ox (per 10 ppb) } & lag01 & $1.024(0.969,1.082)$ & $1.021(0.948,1.099)$ & $0.957(0.876,1.045)$ \\
\hline & $\operatorname{lag} 23$ & $1.005(0.948,1.066)$ & $1.023(0.946,1.105)$ & $0.939(0.854,1.032)$ \\
\hline & $\operatorname{lag} 46$ & $0.989(0.933,1.047)$ & $0.950(0.882,1.024)$ & $1.006(0.914,1.108)$ \\
\hline \multirow[t]{3}{*}{$\mathrm{NO}_{2}($ per $10 \mathrm{ppb})$} & $\operatorname{lag} 01$ & $1.008(0.930,1.093)$ & $0.960(0.840,1.097)$ & $0.976(0.878,1.084)$ \\
\hline & $\operatorname{lag} 23$ & $1.112(1.022,1.209)$ & $1.043(0.914,1.190)$ & $1.065(0.950,1.194)$ \\
\hline & $\operatorname{lag} 46$ & $1.043(0.954,1.140)$ & $1.080(0.937,1.245)$ & $0.975(0.868,1.094)$ \\
\hline \multirow[t]{3}{*}{$\mathrm{SO}_{2}($ per $10 \mathrm{ppb})$} & $\operatorname{lag} 01$ & $0.965(0.677,1.376)$ & $1.469(0.835,2.585)$ & $0.503(0.312,0.811)$ \\
\hline & $\operatorname{lag} 23$ & $1.273(0.900,1.802)$ & $1.028(0.597,1.770)$ & $0.994(0.620,1.594)$ \\
\hline & $\operatorname{lag} 46$ & $1.002(0.693,1.447)$ & $1.255(0.714,2.206)$ & $0.689(0.420,1.129)$ \\
\hline \multicolumn{5}{|l|}{ Multi-pollutant models } \\
\hline \multirow[t]{3}{*}{ SPM $\left(\right.$ per $10 \mu \mathrm{g} / \mathrm{m}^{3}$ ) } & lag01 & $0.977(0.944,1.012)$ & $0.971(0.922,1.023)$ & $0.987(0.943,1.033)$ \\
\hline & $\operatorname{lag} 23$ & $1.032(0.993,1.074)$ & $1.050(0.993,1.109)$ & $1.068(1.008,1.132)$ \\
\hline & $\operatorname{lag} 46$ & $0.977(0.934,1.022)$ & $0.985(0.930,1.043)$ & $0.965(0.891,1.044)$ \\
\hline \multirow[t]{3}{*}{ Ox (per 10 ppb) } & $\operatorname{lag} 01$ & $1.034(0.962,1.111)$ & $1.006(0.921,1.100)$ & $0.908(0.773,1.066)$ \\
\hline & $\operatorname{lag} 23$ & $1.017(0.943,1.098)$ & $1.009(0.918,1.108)$ & $1.013(0.853,1.203)$ \\
\hline & $\operatorname{lag} 46$ & $0.993(0.923,1.068)$ & $0.939(0.860,1.027)$ & $1.040(0.869,1.244)$ \\
\hline \multirow[t]{3}{*}{$\mathrm{NO}_{2}($ per $10 \mathrm{ppb})$} & $\operatorname{lag} 01$ & $1.047(0.924,1.186)$ & $0.898(0.748,1.077)$ & $1.014(0.809,1.272)$ \\
\hline & $\operatorname{lag} 23$ & $1.128(0.991,1.283)$ & $1.042(0.870,1.249)$ & $1.189(0.933,1.516)$ \\
\hline & $\operatorname{lag} 46$ & $1.042(0.913,1.189)$ & $1.037(0.861,1.249)$ & $1.059(0.822,1.365)$ \\
\hline \multirow[t]{3}{*}{$\mathrm{SO}_{2}($ per $10 \mathrm{ppb})$} & $\operatorname{lag} 01$ & $1.034(0.628,1.702)$ & $2.434(1.161,5.103)$ & $0.442(0.211,0.924)$ \\
\hline & $\operatorname{lag} 23$ & $0.755(0.466,1.223)$ & $0.566(0.273,1.172)$ & $0.480(0.232,0.991)$ \\
\hline & lag46 & $1.177(0.706,1.962)$ & $1.587(0.757,3.326)$ & $0.784(0.335,1.834)$ \\
\hline
\end{tabular}

lag0 Case day, lag 1-lag6 number of days prior to case day, lag01 averaged concentration during lag0-lag1, lag23 averaged concentration during lag2-lag3, lag46 averaged concentration during lag4-lag6, CI confidence interval

Table 5 Odds ratio and 95\% confidence interval of asthma hospitalization per $10 \mu \mathrm{g} / \mathrm{m}^{3}$ increase in SPM stratified by AD days

\begin{tabular}{|c|c|c|c|}
\hline \multirow[t]{2}{*}{ Variables } & \multicolumn{3}{|l|}{ Odds ratio $(95 \% \mathrm{CI})$} \\
\hline & lag01 & $\operatorname{lag} 23$ & $\operatorname{lag} 46$ \\
\hline AD days & $0.964(0.876,1.060)$ & $1.105(1.015,1.203)$ & $1.019(0.902,1.151)$ \\
\hline Non-AD days & $0.976(0.944,1.010)$ & $1.054(1.020,1.090)$ & $0.991(0.959,1.024)$ \\
\hline$p$ for interaction & 0.74 & 0.23 & 0.56 \\
\hline
\end{tabular}

$\mathrm{NO}_{2}$ was significantly associated with an increase in hospitalization for asthma during lag2-lag3. There was neither a significant association between $\mathrm{AD}$ events and asthma hospitalization nor differences in the effect estimates of SPM between AD days and non-AD days.

Although a few published studies have focused on the effects of weather variables on asthma, the results of these are inconsistent [5-8]. As the findings of a number of studies suggested that temperature fluctuation could have an impact on acute events, such as coronary heart disease deaths [14] and stroke [15], we decided to examine the effects of temperature fluctuation on asthma exacerbation. The results of our study show that larger changes in temperature-regardless of direction-were related to a higher risk of asthma hospitalization. However, ambient temperature itself was not associated with asthma hospitalization. The exact mechanism of the effect of temperature is not known, but this result suggests that daily temperature fluctuation has a greater impact on the condition of patients with asthma than the temperature itself. 
We applied a lag-stratified distributed lag model [24] to estimate the effects of air pollutants. Using this model, we found that there was a lag of few days between the environmental exposure to air pollutants and hospitalization for asthma. It is thought that exposure to stimuli induces airway limitation through a direct/indirect pathway within a few minutes [25]. The lag, therefore, may be due to a delay in the recognition of the symptoms and presentation at the hospital. Also, the use of a corticosteroid inhaler may have contributed to a longer lag period. The inhaled corticosteroid is expected to reduce the frequency of asthma exacerbation [26]. Only those who failed to control their symptoms may have required emergency hospitalization a few days after the first asthma attack.

The current focus on particulate air pollutants is the regional variation of their health effects. It has been suggested that there is a degree of heterogeneity in the effect of particulate matter on mortality within the same country $[27,28]$. It is therefore possible that there is regional heterogeneity in the effect of particulate matter on disease morbidity. In this study, we found that SPM was significantly associated with hospitalization for asthma. In contrast, Yamazaki et al. [13] did not observe an association in their study conducted in Tokyo. This difference in the results could be partly a result of regional variation in the chemical composition of particles. Ostro et al. [29] observed associations between several components of particles, such as elemental carbon, organic carbon, sulfates, and nitrates, and asthma hospitalization among children. They also suggested that the presence of several metals in particles may increase the risk of hospitalization. Studies investigating the effects of particle composition and asthma are scarce, and this association warrants further examination.

Among the gaseous air pollutants, only $\mathrm{NO}_{2}$ was significantly associated with hospitalization for asthma, but the association became insignificant after adjustment for co-pollutants. Findings from previous epidemiological studies have been inconsistent in showing an effect of gaseous pollutants on asthma episodes [9, 10, 13, 30], possibly because of differences in the level of each gaseous pollutant. A significant association between $\mathrm{SO}_{2}$ and asthma was observed in areas where the level of $\mathrm{SO}_{2}$ was relatively high. In addition, individual differences in susceptibility to air pollutants, such as sex and age, may influence the results [30]. It has been suggested that there could be a threshold of ozone concentration above which there is an increase in the risk of asthma hospitalization [30]. Thus, if the effect of Ox had a threshold and the Ox level in the study area was lower than the threshold, no association would be observed. In our study, all daily mean Ox concentrations were lower than 70 parts per billion (ppb), and there were only 4 days during the study period when the daily maximum Ox concentration was higher than $70 \mathrm{ppb}$. Thus, the Ox level may have been lower than the threshold level. Another possibility is that the health effect of Ox varies according to individual characteristics. Stieb et al. [11] reported that the effect of ozone differed between adults and children. Long-term monitoring in Japan shows a recent increasing trend in Ox concentration [31], and further studies focusing on the threshold of an Ox effect and individual sensitivity are warranted.

We observed stronger association of $\mathrm{SO}_{2}$ at lag01 with asthma hospitalization in the warmer season. A few previous studies also found that the effects of air pollutants were larger during the warm season than during the colder one $[9,13]$. The authors of these reports suggested that this effect could be explained by the simple fact that people tend to spend more time outside in warmer weather, which could reduce exposure misclassification. Contrary to gaseous pollutants, we did not observe any seasonal difference in the effect of SPM on hospitalization for asthma. A more rigorous study on this effect would have to take the difference in both seasonal variation and chemical components of particulate matter into account.

There are concerns that particles from AD have potential toxic effects on human health. Experimental studies using animal models found that exposure to $\mathrm{AD}$ induced lung inflammation [32-35]. Ichinose et al. [33] suggested that lipopolysaccharide and $\beta$-glucan in $\mathrm{AD}$ could cause inflammation of the lungs. Some epidemiological studies have been conducted in Asia, but the results are inconsistent. Chiu et al. [36] found no difference in hospitalization for chronic obstructive pulmonary disease (COPD) between AD event days and non-AD event days in Taiwan. In contrast, Chan et al. [37] reported that hospital visits for COPD increased during $\mathrm{AD}$ days with a high particulate matter concentration. These authors also found that hospitalization for pneumonia significantly increased during AD event days in Taiwan. The results of a study in Minchin, China, where AD events with relatively higher concentrations of particulate matter occur more frequently, indicated that there was a significant association between $\mathrm{AD}$ days and hospitalization for respiratory disease; however, the authors made no adjustment for confounding by air pollutants [38]. In our study, the risk of asthma hospitalization increased by about $20 \%$ on AD days compared to non-AD days although the association was insignificant. The association between SPM and hospitalization at lag23 was significantly positive on both $\mathrm{AD}$ days and non-AD days. However, we did not observe a significant difference in the effect of SPM on asthma hospitalization between AD days and non-AD days. The interpretation of these results is difficult. Given that the AD events increased the risk of hospitalization for asthma and the fact that we failed to detect any significant association because of the limited 
statistical power of our study, it is possible that an $\mathrm{AD}$ event had an adverse health effect only because it presented a high level of SPM and that there was, in fact, no additive effect of particles from AD. Further study is needed across multiple areas to elucidate the health effect of AD events.

There are several limitations to our study. First, we used the measurements at the monitoring station closest to the hospital as a proxy of personal exposure; this could lead to exposure misclassification. Second, we used information on $\mathrm{AD}$ events from the Japan Meteorological Agency. Given that the definition of an AD event is dependent on the distance of visibility, misclassification of $\mathrm{AD}$ events may have occurred on the day when the local particulate pollutant level was high because visibility is determined by the size and amount of particles. Third, this study used the data on visits to the emergency department from one hospital only, which may have resulted in limited statistical power to detect the differences among subgroups in the stratified analyses.

In summary, we explored the effect of various environmental factors on asthma exacerbation. Temperature fluctuation, SPM, and $\mathrm{NO}_{2}$ were found to be associated with an increased risk of hospitalization of children for asthma. We did not observe a significant association between asthma hospitalization and $\mathrm{AD}$ events nor was there a significant difference in the effect of SPM on asthma hospitalization between AD days and non-AD days. These findings provide further evidence of the effects of environmental factors on human health.

\section{References}

1. Nishima S, Chisaka H, Fujiwara T, Furusho K, Hayashi S, Hiraba K, Kanaya M, Kobayashi N, Kuda N, Kumamoto T, Maeda T, Murayama A, Nagata Y, Narukami H, Nishikawa K, Nishio K, Odajima H, Oka S, Okabe T, Okazaki K, Okazaki T, Okuma M, Ota K, Satomi K, Shimomura M, Suda M, Sunagawa I, Tanaka O. Surveys on the prevalence of pediatric bronchial asthma in Japan: a comparison between the 1982, 1992, and 2002 surveys conducted in the same region using the same methodology. Allergol Int. 2009;58:37-53.

2. Braman SS. The global burden of asthma. Chest. 2006;130:4S$12 \mathrm{~S}$.

3. Suissa S, Ernst P. Use of anti-inflammatory therapy and asthma mortality in Japan. Eur Respir J. 2003;21:101-4.

4. Bateman ED, Hurd SS, Barnes PJ, Bousquet J, Drazen JM, FitzGerald M, Gibson P, Ohta K, O'Byrne P, Pedersen SE, Pizzichini E, Sullivan SD, Wenzel SE, Zar HJ. Global strategy for asthma management and prevention: GINA executive summary. Eur Respir J. 2008;31:143-78.

5. de Diego Damia A, Leon Fabregas M, Perpina Tordera M, Compte Torrero L. Effects of air pollution and weather conditions on asthma exacerbation. Respiration. 1999;66:52-8.

6. Abe T, Tokuda Y, Ohde S, Ishimatsu S, Nakamura T, Birrer RB. The relationship of short-term air pollution and weather to ED visits for asthma in Japan. Am J Emerg Med. 2009;27:153-9.
7. Ho WC, Hartley WR, Myers L, Lin MH, Lin YS, Lien CH, Lin RS. Air pollution, weather, and associated risk factors related to asthma prevalence and attack rate. Environ Res. 2007;104:402-9.

8. Lipsett M, Hurley S, Ostro B. Air pollution and emergency room visits for asthma in Santa Clara County, California. Environ Health Perspect. 1997;105:216-22.

9. Barnett AG, Williams GM, Schwartz J, Neller AH, Best TL, Petroeschevsky AL, Simpson RW. Air pollution and child respiratory health: a case-crossover study in Australia and New Zealand. Am J Respir Crit Care Med. 2005;171:1272-8.

10. Villeneuve PJ, Chen L, Rowe BH, Coates F. Outdoor air pollution and emergency department visits for asthma among children and adults: a case-crossover study in northern Alberta, Canada. Environ Health. 2007;6:40.

11. Stieb DM, Burnett RT, Beveridge RC, Brook JR. Association between ozone and asthma emergency department visits in Saint John, New Brunswick, Canada. Environ Health Perspect. 1996;104:1354-60.

12. Tecer LH, Alagha O, Karaca F, Tuncel G, Eldes N. Particulate matter $(\operatorname{PM}(2.5), \operatorname{PM}(10-2.5)$, and $\operatorname{PM}(10))$ and children's hospital admissions for asthma and respiratory diseases: a bidirectional case-crossover study. J Toxicol Environ Health A. $2008 ; 71: 512-20$

13. Yamazaki S, Shima M, Ando M, Nitta H. Modifying effect of age on the association between ambient ozone and nighttime primary care visits due to asthma attack. J Epidemiol. 2009;19:143-51.

14. Cao J, Cheng Y, Zhao N, Song W, Jiang C, Chen R, Kan H. Diurnal temperature range is a risk factor for coronary heart disease death. J Epidemiol. 2009;19:328-32.

15. Kyobutungi C, Grau A, Stieglbauer G, Becher H. Absolute temperature, temperature changes and stroke risk: a case-crossover study. Eur J Epidemiol. 2005;20:693-8.

16. Husar RB, Tratt DM, Schichtel BA, Falke SR, Li F, Jaffe D, Gasso S, Gill T, Laulainen NS, Lu F, Reheis MC, Chun Y, Westphal D, Holben BN, Gueymard C, McKendry I, Kuring N, Feldman GC, McClain C, Frouin RJ, Merrill J, DuBois D, Vignola F, Murayama T, Nickovic S, Wilson WE, Sassen K, Sugimoto N, Malm WC. Asian dust events of April 1998. J Geophys Res Atmos. 2001;106:18317-30.

17. Yang CY, Tsai SS, Chang CC, Ho SC. Effects of Asian dust storm events on daily admissions for asthma in Taipei, Taiwan. Inhal Toxicol. 2005;17:817-21.

18. Bell ML, Levy JK, Lin Z. The effect of sandstorms and air pollution on cause-specific hospital admissions in Taipei, Taiwan. Occup Environ Med. 2008;65:104-11.

19. Mori I, Nishikawa M, Tanimura T, Quan H. Change in size distribution and chemical composition of kosa (Asian dust) aerosol during long-range transport. Atmos Environ. 2003;37:4253-63.

20. Ho HM, Rao CY, Hsu HH, Chiu YH, Liu CM, Chao HJ. Characteristics and determinants of ambient fungal spores in Hualien, Taiwan. Atmos Environ. 2005;39:5839-50.

21. The Japan Meteorological Agency Asian dust: the databank for global environment (in Japanese). Available at: http://www.data. kishou.go.jp/obs-env/kosahp/kosa_data_index.html. Accessed 11 Nov 2009.

22. The Japan Meteorological Agency Information on Asian dust and aerosol (in Japanese). Available at: http://www.data.kishou.go.jp/ obs-env/aerosolhp/index.html. Accessed 11 Nov 2009.

23. Maclure M. The case-crossover design: a method for studying transient effects on the risk of acute events. Am J Epidemiol. 1991;133:144-53.

24. Armstrong B. Models for the relationship between ambient temperature and daily mortality. Epidemiology. 2006;17:624-31.

25. Van Schoor J, Joos GF, Pauwels RA. Indirect bronchial hyperresponsiveness in asthma: mechanisms, pharmacology and implications for clinical research. Eur Respir J. 2000;16:514-33. 
26. Bisgaard H, Munck SL, Nielsen JP, Petersen W, Ohlsson SV. Inhaled budesonide for treatment of recurrent wheezing in early childhood. Lancet. 1990;336:649-51.

27. Dominici F, McDermott A, Zeger SL, Samet JM. National maps of the effects of particulate matter on mortality: exploring geographical variation. Environ Health Perspect. 2003;111:39-44.

28. Ueda K, Nitta H, Ono M, Takeuchi A. Estimating mortality effects of fine particulate matter in Japan: a comparison of timeseries and case-crossover analyses. J Air Waste Manag Assoc. 2009;59:1212-8.

29. Ostro B, Roth L, Malig B, Marty M. The effects of fine particle components on respiratory hospital admissions in children. Environ Health Perspect. 2009;117:475-80.

30. Lin M, Chen Y, Burnett RT, Villeneuve PJ, Krewski D. Effect of short-term exposure to gaseous pollution on asthma hospitalisation in children: a bi-directional case-crossover analysis. J Epidemiol Community Health. 2003;57:50-5.

31. Sadanaga Y, Shibata S, Hamana M, Takenaka N, Bandow H. Weekday/weekend difference of ozone and its precursors in urban areas of Japan, focusing on nitrogen oxides and hydrocarbons. Atmos Environ. 2008;42:4708-23.

32. Ichinose T, Sadakane K, Takano H, Yanagisawa R, Nishikawa M, Mori I, Kawazato H, Yasuda A, Hiyoshi K, Shibamoto T. Enhancement of mite allergen-induced eosinophil infiltration in the murine airway and local cytokine/chemokine expression by Asian sand dust. J Toxicol Environ Health A. 2006;69:1571-85.
33. Ichinose T, Nishikawa M, Takano H, Sera N, Sadakane K, Mori $\mathrm{K}$, Yanagisawa R, Oda $\mathrm{T}$, Tamura $\mathrm{H}$, Hiyoshi $\mathrm{K}$, Quan $\mathrm{H}$, Tomura S, Shibamoto T. Pulmonary toxicity induced by intratracheal instillation of Asian yellow dust (Kosa) in mice. Environ Toxicol Pharmacol. 2005;20:48-56.

34. Hiyoshi K, Ichinose T, Sadakane K, Takano H, Nishikawa M, Mori I, Yanagisawa R, Yoshida S, Kumagai Y, Tomura S, Shibamoto T. Asian sand dust enhances ovalbumin-induced eosinophil recruitment in the alveoli and airway of mice. Environ Res. 2005;99:361-8.

35. Lei YC, Chan CC, Wang PY, Lee CT, Cheng TJ. Effects of Asian dust event particles on inflammation markers in peripheral blood and bronchoalveolar lavage in pulmonary hypertensive rats. Environ Res. 2004;95:71-6.

36. Chiu HF, Tiao MM, Ho SC, Kuo HW, Wu TN, Yang CY. Effects of Asian dust storm events on hospital admissions for chronic obstructive pulmonary disease in Taipei, Taiwan. Inhal Toxicol. 2008;20:777-81.

37. Chan CC, Chuang KJ, Chen WJ, Chang WT, Lee CT, Peng CM. Increasing cardiopulmonary emergency visits by long-range transported Asian dust storms in Taiwan. Environ Res. 2008;106:393-400.

38. Meng ZQ, Lu B. Dust events as a risk factor for daily hospitalization for respiratory and cardiovascular diseases in Minqin, China. Atmos Environ. 2007;41:7048-58. 